\title{
OSTEOPOROSIS SECONDARY TO CROUZON SYNDROME
}

Paloma Medeiros Gomes Cavalcanti1 ', , Aleuda Cartaxo Moura Rodrigues de Aquino', Ana Flávia Henriques Ribeiro Monteiro', Fellipe Augusto da Câmara Pires Belmont', Guilherme Arcoverde Pinto', Lucas Galvão Araújo', Maria Laura Cabral Dantas', Pablo Duarte Lima', Tereza Patrícia Acebey Crespo ${ }^{1}$

1.Centro Universitário de João Pessoa, João Pessoa (PB), Brazil.

*Corresponding author: palomaamedeiros15@gmail.com

\section{BACKGROUND}

Osteoporosis is an osteometabolic disease that comes about to decreased bone mass, leading patients affected by to be more susceptible to fractures. Crouzon Syndrome (CS) is a rare, autosomal dominant genetic disorder, with no predilection for race or sex, caused by a mutation in the gene responsible for coding the type 2 fibroblast growth factor receptors (FGFR-2), which results in early closure of cranial sutures. In addition, FGFR-2 is also essential for osteogenesis and bone mineralization by osteoblasts. For this reason, patients who have a mutation in this gene, such as CS, may present deficiency in calcification, which leads to secondary osteoporosis.

\section{CASE REPORT}

Male patient, 44 years old, with CS, submitted to corrective craniosynostosis surgery 43 years ago, son of a healthy mother and father, with a sister who also had CS. He reports a fracture of the femur due to a fall from his own height 8 years ago, without bone callus formation, being necessary after 2 years, to have total hip arthroplasty on the left side, and later on the right side in 2017, because of arthrosis. The patient had previous bone densitometry, in which he presented osteopenia in the femoral neck (T score of -2.36).

\section{CONCLUSION}

The concomitance of CS and the onset of secondary osteoporosis is common, but there are no reports in the literature correlating the two diseases. However, patients with this syndrome have a FGFR2 gene mutation, leading to a deficiency in calcification, which can lead to secondary osteoporosis, since the proper functioning of this gene is essential for osteogenesis. Knowledge about the presentation of the two diseases is extremely important, since both are progressive diseases and a late diagnosis and treatment can result in irreversible damage and sequelae for the quality of life of patients, thus, the diagnosis and the establishment of early treatment of osteoporosis in these patients would help prevent low impact fractures and improve the morbidity and totality of these events. 